\title{
THE EFFECT OF DEGREE AND TYPE OF LEFT VENTRICULAR HYPERTROPHY ON VENTRICULAR ARRHYTHMIAS IN HYPERTENSION
}

\author{
Ivan S. Tasic ${ }^{1,2 *}$, Dragan Djordjevic ${ }^{1,2}$, Svetlana Kostic ${ }^{1}$ \\ ${ }^{1}$ Institute for Cardiology and Rheumatology Niška Banja, Niš, Serbia \\ ${ }^{2}$ Faculty of Medicine, University of Niš, Niš, Serbia
}

\begin{abstract}
Finding the arrythmogenic potential in patients with arterial hypertension as well as its correlation with left ventricular hypertrophy $(L V H)$, and its type and degree. The research included 109 hypertensive patients (pts) (54 male and 55 female), $54.2 \pm 7.9$ years old without symptomatic coronary disease, myocardial infarction and systolic dysfunction. All the pts had a clinical examination, ECG, $24 \mathrm{~h}$ Holter monitoring with Lown classification of ventricular arrhythmias, an echocardiogram with left ventricular mass index (LVMI) and a specific type of LVH. QT interval dispersion (QTd) was calculated on 12 leads standard ECG. 75 pts had LVH (LVMI: $172.6 \pm 42.95 \mathrm{~g} / \mathrm{m} 2$ ) while 35 pts were without LVH (109.3 $\pm 15.9 \mathrm{~g} / \mathrm{m} 2)$. Non sustained ventricular tachycardia was registered in $13 \mathrm{pts}(17.6 \%)$ with LVH and 1 female patient without LVH (2.9\%). Patients with VT had a considerably higher ILVM (214.9 \pm 6.8 vs. 151.9 $\pm 47.2 \mathrm{~g} / \mathrm{m} 2)$ than the average and higher QTd $(73.7 \pm 19.1 \mathrm{vs}$. $55.2 \pm 20.2)$. VT was registered in $3 / 19(15.8 \%)$ with eccentric nedilated type LVH, 6/38 (15.8\%) with concentric LVH, $1 / 11$ (9.1) (disproportional septal LVH) and 3/5 (60\%) with dilated LVH. Univariate analysis showed a considerable correlation between the degree of arrhythmias and ILVM $(p<0.001)$ and QTd $(p=0.012)$. Ventricular arrhythmias in patients with arterial hypertension are considerably correlated to the degree of LVH expressed in ILVM and QTd.
\end{abstract}

Key words: hypertension, left ventricular hypertrophy, ventricular arrhythmia, QT.

\section{Introduction}

The increased thickness of the left ventricular wall and enlargement of the left ventricular cavity that may accompany hypertension have a compensatory value in that the heart is better able to maintain stroke volume in the face of an increased afterload. As the structural changes progress, however, cardiac function diminishes and either concentric and eccentric left ventricular hypertrophy $(\mathrm{LVH})$ develops. The change represents an additional risk factor for all types of cardiovascular disease in hypertensive patients [1].

Left ventricular hypertrophy on the electrocardiogram (ECG) has been identified as a major risk factor for cardiovascular disease for more than 35 years. The data from the Framingham Heart Study also showed that the detection of LVH by echocardiography provides persuasive prognostic information beyond that derived from traditional risk factors such as blood pressure, smoking, and lipid levels. In that study as well as in the investigation carried out at the New York Hospital-Cornell Medical Center, left ventricular mass and age were the

*Correspondence to: Ivan Tasić, M.D., PhD

Faculty of Medicine, University of Niš, Niš, Dr. Zorana Djindića 81, 18000 Niš, Serbia

Phone: +381648609295

E-mail: dr.ivan.tasic@gmail.com

Received January $11^{\text {th }}, 2017$, accepted for publication February $27^{\text {th }}, 2017$ strongest predictors of prognosis [2]. The importance of LVH is confirmed by the finding that, within 5 years of its appearance, one-third of men and one-fourth of women with LVH are dead [3].

A multivariate analysis demonstrated in men a relative risk of death from cardiovascular disease of 1.73 for each increment of $50 \mathrm{~g} / \mathrm{m}^{2}$ in left ventricular mass. The corresponding value for women was 2.12 . The risk factoradjusted relative risk of sudden death in men was for each increment of $50 \mathrm{~g} / \mathrm{m}^{2}$ in left ventricular mass. In a report restricted to patients with essential hypertension, the multivariate analysis showed that only age and echocardiographic left ventricular mass were independently associated with the cardiovascular death [4].

Analyzing patho-anatomic and electrophysiological characteristics of myocardium in LVH it can be shown that hypertensive myocardium has a tendency to show electric instability and arrhythmias. The hypothesis of hypertrophy per se leading to electrophysiological changes that may trigger lethal arrhythmias may be even more attractive.

It has been suggested that the increased incidence of sudden death in hypertensive patients, particularly those with LVH, may be casually related to the increased number and complexity of ventricular arrhythmias that have been demonstrated in these patients.

Electrophysiological studies suggest that QT prolongation is associated with increased regional 
homogeneity of repolarization, a factor that may contribute to ventricular arrhythmias. Recent clinical studies have suggested that the interload variability of the QT interval in the standard ECG, defined as QT dispersion, reflects regional differences in ventricular repolarization. Increased dispersion of recovery time is believed to increase the risk for serious ventricular arrhythmias. [5,6,7].

In view of this, the aim of our study is to prove whether there is an interrelation between markers of sudden death in hypertensive patients (left ventricular hypertrophy, its degree and type, ventricular arrhythmias and QTc dispersion).

\section{Subjects and Methods}

\section{Subjects}

One hundred and nine consecutive hypertensive patients (pts) (54 male and 55 female), $54.2 \pm 7.9$ years old, treated at the Health Center for Hypertension at the Institute "Niska Banja", were involved in the study. To be included, patients must have trough sitting diastolic blood pressure mean readings of 90 to $115 \mathrm{mmHg}$ or sitting systolic blood pressure mean readings of 160 to $200 \mathrm{mmHg}$ after 1 and 2 weeks without antihypertensive therapy. Patients were excluded if they had clinical or laboratory evidence of heart failure, renal failure, coronary artery disease, valvular defect, or secondary causes of hypertension.

\section{Electrocardiography}

Standard 12-lead ECGs were recorded with a paper speed of 25 or $50 \mathrm{~mm} / \mathrm{s}$. ECGs of technically good quality were recorded. QT interval analysis was done on 12-lead ECGs taken upon enrolment in the study [8]. A single observer measured QT interval in all leads, if possible, on a surface 12-lead ECG $(25 \mathrm{~mm} / \mathrm{s}$ speed). QT interval was taken from onset of the QRS to the end of the $\mathrm{T}$ wave (i.e., return to the $\mathrm{T} / \mathrm{P}$ baseline). If $\mathrm{U}$ waves were present, the QT interval was measured to the nadir of the curve between the $\mathrm{T}$ and $\mathrm{U}$ waves. Three consecutive cycles were measured for each lead. QT intervals were corrected with Basset's formula (QTc=QT/RR sup 1/2). QTc dispersion, defined as the difference between maximum and minimum QTc, was calculated in ECGs in which at least 5 leads were measurable. Adjusted QTc dispersion was measured to correct for the known dependence of the index on the number of measurable leads [9].

\section{Echocardiography}

The echocardiographic studies were performed in the morning, with the subject in a supine left lateral decubitus position, after 30 minutes of rest. Only one physican was responsible for recording the echocardiogram. The measurements of left ventricular wall thickness and chamber diameter were made in diastole in accordance with methods outlined by the American Society of
Echocardiography [10]. Left ventricular mass (LV mass) was estimated by the modified cubed formula using measurements obtained in accordance with the "Penn" convention [11]: LV mass $(\mathrm{g})=1.04$ [(LVID + VST + PWT $\left.)^{3}-(\text { LVID })^{3}\right]-13.6$, where LVID is left ventricular internal dimension, VST is ventricular septal thickness, and PWT is posterior left ventricular wall thickness. LV mass indexed by body surface area $\left(\mathrm{g} / \mathrm{m}^{2}\right)$. Cut-off values for LVH by Penn convention $\left(\mathrm{g} / \mathrm{m}^{2}\right)$ criteria were $\geq 134$ $\mathrm{g} / \mathrm{m}^{2}$ for men and $\geq 110 \mathrm{~g} / \mathrm{m}^{2}$ for women. Left ventricular wall thickness was defined as sum VST and PWT, relative wall thickness was defined as (left ventricular wall thickness/LVID)x100\% and index LVID (LVID/ body surface area). On the basis of these parameters 4 types of LVH are defined: 1) concentric hypertrophy-C; 2) eccentric no dilated LVH - END, 3) eccentric dilated LVH - ED and 4) disproportional septal LVH - DS [12].

\section{Ambulatory electrocardiographic monitoring}

Twenty-four hour ambulatory ECGs were recorded with sistem Del Mar Avionics, model 465; Irvine, California during each subject's normal activities. Evaluation of premature ventricular complex followed the grading system of Lown and Wolf [13]. Grade 0, no premature ventricular complex; Grade 1,<30 premature ventricular complex/h; Grade 2, >30 premature ventricular complex/h; Grade 3, multiform prematureventricular complex; Grade 4A, couplets; Grade 4B, run of ventricular tachycardia (VT) (3 or more consecutive premature ventricular complex). Lown Grade $\geq 3$ were considered as complex ventricular arrhythmias. Since the classification suggested by Lown and Wolf combines prevalence with morphology of ventricular ectopy, in a second analysis we compared hypertensive patients with complex ventricular ectopy with those without commplex ventricular ectopy.

\section{Statistical analysis}

The data from individual patients were summarized as mean \pm SD. The statistical significance of differences in correlation coefficients and mean values was examined by ANOVA and by Student's $t$ test for unpaired observations. A value of $\mathrm{P}<0.05$ was taken as the minimal level of statistical significance. Statistical tests were carried using STATISTICA programs.

\section{Results}

From 109 hypertensive patients included in this study, 74 pts had echocardiographic evidence of left ventricular hypertrophy while 35 did not. There were no differences between the groups in terms of sex, body surface area and cholesterol degree. Systolic blood pressure, left ventricular mass index, the frequency of ventricular tachycardia and QTc dispersion were statistically significantly higher $(\mathrm{p}<0.05)$ in the patients with echocardiographic LV hypertrophy (Table 1$)$. 
Table 1 Clinical and hemodynamic characteristics of hypertensive patients with and without left ventricular hypertrophy established by echocardiographically.

\begin{tabular}{lcc}
\hline & Echo LVH $(\mathrm{n}=74)$ & Echo no LVH $(\mathrm{n}=35)$ \\
\hline Age $(\mathrm{yr})$ & $55.3 \pm 7.8^{*}$ & $51.7 \pm 7.5$ \\
Body surface area $\left(\mathrm{m}^{2}\right)$ & $1.91 \pm 0.2$ & $1.87 \pm 0.2$ \\
Sex (male:female ratio) & $38 / 36$ & $16 / 19$ \\
Systolic pressure (mm Hg) & $169.4 \pm 16^{* *}$ & $158.1 \pm 12.7$ \\
Diastolic pressure (mm Hg) & $106.6 \pm 15$ & $104.6 \pm 7$ \\
Heart rate (beats/min) & $75.1 \pm 9$ & $72.9 \pm 8.2$ \\
Left ventricular mass index g/m ${ }^{2}$ & $172.6 \pm 43^{* *}$ & $109.3 \pm 16$ \\
IVb degree Lown (n) & $13(18 \%)^{*}$ & $1(3 \%)$ \\
QTc ms & $434.6 \pm 28.5$ & $421 \pm 31$ \\
QTc dispersion & $58.8 \pm 20^{*}$ & $48.3 \pm 20$ \\
Cholesterol & $6.2 \pm 1.1$ & $6.1 \pm 21.3$ \\
\hline Values are &
\end{tabular}

Values are expressed as means \pm SEM $,{ }^{*} \mathrm{p}<0.05,{ }^{* *} \mathrm{p}<0.01$

Table 2 Clinical and hemodynamic characteristics of hypertensive patients with different types of LVH

\begin{tabular}{lcccc}
\hline & C LVH $(\mathrm{n}=38)$ & END LVH $(\mathrm{n}=19)$ & ED LVH $(\mathrm{n}=6)$ & DS LVH $(\mathrm{n}=11)$ \\
\hline Age (yr) & $54.6 \pm 7.3$ & $56.9 \pm 8.6$ & $61.2 \pm 4.8$ & $51.4 \pm 8.3$ \\
Body surface area $\left(\mathrm{m}^{2}\right)$ & $1.87 \pm 0.15$ & $1.9 \pm 0.2$ & $1.96 \pm 0.1$ & $1.92 \pm 0.1$ \\
Sex (male:female ratio) & $16 / 22$ & $11 / 8$ & $6 / 0$ & $6 / 5$ \\
Systolic pressure (mm Hg) & $172 \pm 16$ & $169.5 \pm 18.4$ & $162 \pm 15$ & $160.5 \pm 12$ \\
Diastolic pressure (mm Hg) & $109.6 \pm 10$ & $105.3 \pm 11$ & $103 \pm 4.5$ & $106.8 \pm 6.4$ \\
Heart rate (beats/min) & $75 \pm 8.6$ & $73.1 \pm 10$ & $82.5 \pm 13$ & $77.2 \pm 8$ \\
Left ventricular mass index g/m ${ }^{2}$ & $166.8 \pm 40.3$ & $172.4 \pm 23$ & $260 \pm 62 . *^{*}$ & $152.7 \pm 21.5$ \\
IVb degree Lown (n) & $6(16 \%)$ & $3(16 \%)$ & $3(50 \%)$ & $1(9 \%)$ \\
QTc ms & $433.3 \pm 25.2$ & $430.8 \pm 35.1$ & $461.7 \pm 24$ & $442 \pm 28.1$ \\
QTc dispersion & $54.3 \pm 14.1$ & $62 \pm 20.1$ & $92.5 \pm 38.4$ & $58.2 \pm 11$ \\
Cholesterol & $6.12 \pm 1.1$ & $6.7 \pm 1$ & $5.9 \pm 1.6$ & $6.15 \pm 1.2$ \\
\hline
\end{tabular}

Values are expressed as means \pm SEM, ${ }^{*} \mathrm{p}<0.05$

\section{Type left ventricular hypertrophy}

Most hypertensive pts had LVH of a concentric type, while a small but significant group of pts had a dilated LVH. This group was significantly different from the pts with other LVH types since they were older, they had lower systolic blood pressure, a high degree LVH (LV mass index: $\left.260 \pm 62.5 \mathrm{~g} / \mathrm{m}^{2}\right)$, proportionally greater frequency of ventricular tachycardia and bigger QTc dispersion (Table 2). The examined parameters did not show any other significant differences in patients with other LVH types except for the fact that the patients with disproportional septal LVH were younger, had lower systolic blood pressure and lower LV mass index.

\section{Relationship between left ventricular mass index and examined parameters}

Systolic blood pressure $(r=0.27, p=0.0047)$ and heart rate $(\mathrm{r}=0.25, \mathrm{p}=0.016)$ are closely connected to the degree of left ventricular hypertrophy. The interconnection is even more prominent between left ventricular mass index and QTc dispersion $(\mathrm{r}=0.34, \mathrm{p}=0.004)$. The frequency of ventricular arrhythmias graded according to
Lown-Wolf is strictly correlated with seriousness of left ventricular hypertrophy $(\mathrm{r}=0.4, \mathrm{p}=0.00002)$ (Table 3$)$.

Table 3 Correlation coefficients relating clinical and haemodynamic data to left ventricular mass index

\begin{tabular}{ll}
\hline & ILVM \\
\hline Age (yr) & 0.17 \\
Body surface area $\left(\mathrm{m}^{2}\right)$ & 0.13 \\
Systolic pressure $(\mathrm{mm} \mathrm{Hg})$ & $0.27^{* *}$ \\
Diastolic pressure $(\mathrm{mm} \mathrm{Hg})$ & 0.07 \\
Heart rate (beats/min) & $0.25^{*}$ \\
Lown-Wolf degree & $0.4^{* * *}$ \\
QTc ms & 0.14 \\
QTc dispersion & $0.34^{* *}$ \\
Cholesterol & 0.03 \\
\hline *p<0.05, ${ }^{* *} \mathrm{p}<0.005, * * * \mathrm{p}<0.001$ &
\end{tabular}

Fig 1 and Table 4 show significant correlation between two examined markers of sudden death in our study. More serious degree of ventricular arrhythmias was accompanied by longer QTc, bigger QT dispersion and higher LV mass index. 


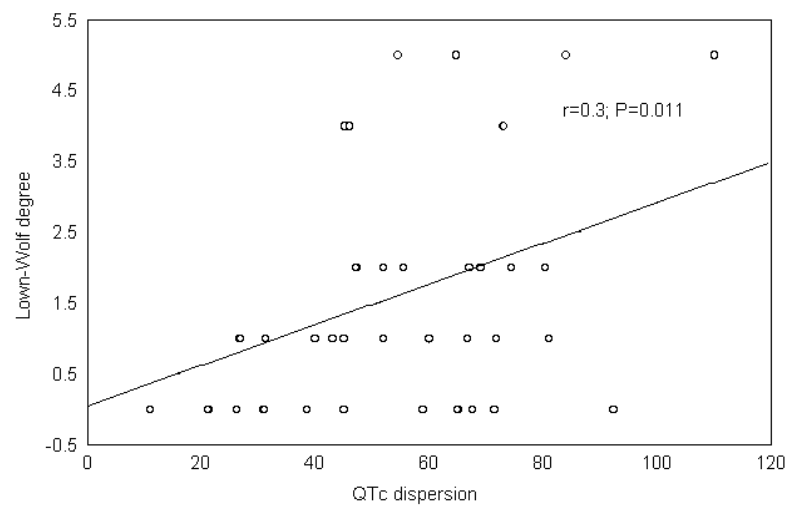

Fig. 1 Scatter plots illustrating the relationship of the premature ventricular complexes (Lown-Wolf) to the QT dispersion.

Table 4 Relationship between dispersion parameters and the grade of premature ventricular complexes.

\begin{tabular}{lcc}
\hline & $0-2^{*}$ & $3-4$ \\
\hline LVM index & $144 \pm 35.3^{* *}$ & $185.2 \pm 58.5$ \\
QTc & $425.7 \pm 28.4^{* *}$ & $443.5 \pm 27.3$ \\
QTc dispersion & $52.15 \pm 18^{* *}$ & $64 \pm 21$ \\
\hline
\end{tabular}

Values are expressed as means \pm SEM , *Lown-Wolf grades $0,1,2$ vs. Lown-Wolf grades $3,4 \mathrm{~A}, 4 \mathrm{~B}$

$\mathrm{p}<0.05$

In $14(13 \%)$ hypertensive patients non-sustained ventricular tachycardia was registered. Almost all patients were male but in other clinical parameters (age, body surface area, blood pressure and heart rate, cholesterol) they did not show any difference from other patients. However, the degree of their hypertrophy and QTc dispersion were significantly different compared to pts who did not have VT (Table 5).

Table 5 Clinical characteristics of patients with registered VT.

\begin{tabular}{lc}
\hline Age $(\mathrm{yr})$ & $57.4 \pm 9$ \\
Body surface area $\left(\mathrm{m}^{2}\right)$ & $1.9 \pm 0.1$ \\
Sex (male:female ratio) & $10 / 3$ \\
Systolic pressure $(\mathrm{mm} \mathrm{Hg})$ & $168.6 \pm 18$ \\
Diastolic pressure $(\mathrm{mm} \mathrm{Hg})$ & $108.2 \pm 12$ \\
Heart rate (beats/min) & $76.9 \pm 12.1$ \\
Left ventricular mass index g/m & $214.9 \pm 68.4$ \\
QTc ms & $442.3 \pm 28$ \\
QTc dispersion & $73.7 \pm 19$ \\
Cholesterol & $6.1 \pm 1.4$ \\
\hline
\end{tabular}

Values are expressed as means \pm SEM,

\section{Discussion}

Our research shows that the increase of left ventricular mass is closely correlated with frequency of ventricular arrhythmias and QTc dispersion. Knowing the importance of ventricular arrhythmias and QTc dispersion as markers of sudden death, our results suggest that identification of left ventricular mass in hypertensive pts is a good marker for future prognosis.

The importance of LV hypertrophy in the morbidity of hypertensive disease has been underscored by the number of electrocardiographic and echocardiographic studies that have convincingly demonstrated its importance as an independent predictor of morbidity and mortality $[14,15]$. Not only does LV hypertrophy as a dichotomous variable predict adverse outcome, but the magnitude of LV mass a continuous variable is also associated with cardiovascular risk, even with values for LV mass within the "normal range".

Importantly, there is an association of LV hypertrophy with complex ventricular arrhythmia, a possible processor of sudden death in hypertensive patients, even in patients without coronary artery disease on angiography [16]. In patients with reversible myocardial perfusion defects on thallium scintigraphy, both LV hypertrophy and inducible ischemia are independently associated with ventricular arrhythmias [17]. Using programmed electrical stimulation, Coste et al. [18] demonstrated more intraventricular reentry and non-sustained ventricular tachycardia in hypertensive patients with LV hypertrophy compared to control group.

The pathologic alternant related to ectopic impulse generation in LVH are multifactorial [19] and include enlarged myocytes, the expansion of the collagen matrix, fibrosis, subendocardial ischemia, and medial hypertrophy of the coronary arteries impending homogeneous impulse propagation throughout the myocardium. The arrhythmogenic substrate of LV hypertrophy itself may explain reentry mechanisms, such as fibrillar stretching, anisotropy, and triggered activity due to after-potentials, depending on activation of slow calcium channels.

Concentric hypertrophy appears to be associated with a more severe overall prognosis compared with eccentric hypertrophy, whereas concentric remodeling seems to be of intermediate significance compared with normal geometry [20]. Eccentric LV hypertrophy was independently associated with increased risk of sudden cardiac arrest (SCA) in subjects with $\mathrm{EF} \leq 40 \%$ [21]. In our study there was no (statistical) difference in arrhythmias between these two types of LV hypertrophy, however, significantly highest incidence of serious arrhythmia, despite the small number of patients, was registered in patients with ED type. These patients had the highest QT dispersion and the greatest left ventricular mass index.

QT dispersion has been associated with increased risk for ventricular arrhythmias and sudden death in patients with chronic heart failure [9], mitral valve prolapse [22], MI [23], familial long-QT syndrome [24], and with an increased risk for cardiac mortality in patients with peripheral arterial disease, MI and older men and women [25].

Clarkson et al. in their study of multivariate analyses demonstrated significant relationships between QT dispersion and office systolic blood pressure, and left ventricular mass index. Several studies reported that the most typical electrical abnormality associated with 
cardiac hypertrophy is prolongation of the action potential. Left ventricular hypertrophy by severe hypertension induced by renal artery constriction produced a prolongation of action potential duration. An increased dispersion of ventricular refractoriness might represent another electrical consequence of the hypertrophic process. A prolonged duration of ventricular repolarization, in fact may be proarrhythmic, probably favoring the occurrence of after depolarizations and then triggering activity-related arrhythmias [26,27].

The results of our study have shown that QTc dispersion is significantly correlated with the increase of left ventricular mass index and that the highest values are found in pts with eccentric nondilated and eccentric dilated which proves the hypothesis that an important entity underlying QT dispersion is patchy myocardial fibrosis, resulting from ventricular dilatation and neurohormonal activation and myocardial ischemia.
The results of our study have shown a significant correlation between QTc dispersion and the degree of ventricular arrhythmias registered by Holter monitoring. It can be important for better understanding not only of the mechanisms of malignant arrhythmias in pts with LV hypertrophy (QTc dispersion shows differences in action potential duration) but also in estimating the risk that a hypertensive patient carries with himself.

Modern antihypertensive therapy means, among other things, a possibility of regression of left ventricular mass index. Recent studies prove that there is a chance of better prognosis in pts with regression of LV hypertrophy but there is not a study which shows what the arrhythmogenic potential of myocardium is after its regression. The observation of left ventricular mass, ventricular arrhythmias and QTc dispersion can probably answer the question to what degree and how regression of left ventricular hypertrophy are correlated with decrease of electric vulnerability of myocardium and with a risk of sudden death in this group of pts.

\section{References}

1. Mancia G, Giannattasio C, Turrini D, Grassi G, Omboni S. Structural cardiovascular alterations and blood pressure variability in human hypertension. J Hypertens Suppl 1995; 13(suppl 2): S7-S14.

2. Levy D, Garrison RJ, Savage DD, et al. Prognostic implications of echocardiographically-determined left ventricular mass in the Framingham Heart Study. N Engl J Med 1990; 322:1561-1566.

3. Kannel WB. Prevalence and natural history of electrocardiographic left ventricular hypertrophy. Am J Med 1983; 75(suppl 3A):4-11.

4. Almendral J, Villacastin PJ, Arenal A, Tercedor L, Merino LJ, Delcan LJ: Evidence favoring the hypothesis that ventricular arrhythmias have prognostic significance in left ventricular hypertrophy secondary to systemic hypertension. Am J Cardiol 1995; 76:60D-63D.

5. Surawicz B. Electrophysiologic substrate of torsade de pointes: dispersion of repolarization or early after depolarization. J Am Coll Cardiol 1989; 14:172-184.

6. Bianco HT, Izar MC, Póvoa RM, et al. Left ventricular hypertrophy and QTc dispersion are predictors of long term mortality in subjects with type 2 diabetes. Int J Cardiol. 2014; 176(3):1170-1172.

7. Higham PD, Furniss SS, Campbell RWF. QT dispersion and components of the QT interval in ischemia and infarction. Br Heart J 1995; 73:32-36.

8. Dahlof B, Devereux R, et al. The Losartan intervention for endpoint reduction (LIFE) in hypertension study. Rationale, design, and methods. Am J Hypertens 1997; 10:705-713.

9. Barr SG, Naas A, Freeman M, Lang CC, Struthers DA. QT dispersion and sudden unexpected death in chronic heart failure. Lancet 1994; 343:327-329.

10. Marwick TH, Gillebert TC, Aurigemma G, et al. Recommendations on the Use of Echocardiography in Adult Hypertension: A Report from the European Association of Cardiovascular Imaging (EACVI) and the American Society of Echocardiography (ASE). J Am Soc Echocardiogr 2015; 28(7):727-754.

11. Devereux RB, Alonso DR, Lutas EM, Gottlieb GJ, Campo E, Sachs I, Reichek N. Echocardiographic assessment of left ventricular hypertrophy: comparasion to necropsy findings. Am J Cardiol $1986 ; 57: 450-458$.

12. Savage DD, Garrison RJ, Kannel WB, Levy D, Anderson SJ, Strokes J III, Feinleib M, castilli WP. The spectrum of left ventricular hypertrophy in a general population sample: the Framingham Study. Circulation 1987; 75(suppl I):I-26-33.

13. Lown B, Wolf M: Approaches to sudden death from coronary heart disease. Circulation 1971; 44:130-142.

14. Casale PN, Devereux RB, Milner M. Value of echocardiographic measurement of left ventricular mass in predicting cardiovascular

morbid events in hypertensive men. Ann Intern Med 1986; 105:173-178.

15. Levy D, Garrison RJ, Savage DD, et al. Prognostic implications of echocardiographically determined left ventricular mass in the Framingham Heart Study. N Engl J Med 1990; 322:1561-1566.

16. Ghali JK, Kadakia S, Cooper RS, Liao YL. Impact of left ventricular hypertrophy on ventricular arrhythmias in the absence of coronary artery disease. J Am Coll Cardiol 1991; 17:1277-1282.

17. Szlachic J, Tubau JF, O'Kelly B. What is the role of silent coronary artery disease and left ventricular hypertrophy in the genesis of ventricular arrhythmias in men with essential hypertension? J Am Coll Cardiol 1992; 19:803-808.

18. Coste P, Clementy J, Besse P, Bricaud H. Left ventricular hypertrophy and ventricular dysrhythmic risk in hypertensive patients: evaluation by programmed electrical stimulation. J Hypertens 1988; 6: S116-118.

19. Cosin Aguilar J, Hernandez Martinez A, Andreas Conejos F. Mechanisms of ventricular arrhythmias in the presence of pathological hypertrophy. Eur Heart J 1993; 14(suppl J):65-70.

20. Ganau A, Devereux RB, Roman MJ, de Simone G, Pickering TG, Saba PS, et al. patterns of left ventricular hypertrophy and geometric remodeling in essential hypertension. J Am Coll Cardiol 1992; 19:1550-1558.

21. Phan D, Aro AL, Reinier K, Teodorescu C, Uy-Evanado A, Gunson K, Jui J, Chugh SS. Left ventricular geometry and risk of sudden cardiac arrest in patients with severely reduced ejection fraction. J Am Heart Assoc 2016 Aug 18; 5(8).

22. Ticleman RG, Crijus HJ, Wiesfeld AC, Posma J, Hamer HP, Lie $\mathrm{KI}$. Increased dispersion of refractoriness in the absence of QT prolongation in patients with mitral valve prolapse and ventricular arrhythmias. Br Heart J 1995; 73:37-40.

23. Glancy JM, Garratt CJ, Woods KL, de Bono DP. QT dispersion and mortality after myocardial infarction. Lancet 1995; 345: 945-948.

24. Day CP, McComb JM, Campbel RW. QT dispersion: an indication of arrhythmia risk in patients with long QT intervals. Br Heart J 1990; 63:342-344.

25. de Bruyne MC, Hoes AW, Kors JA, Hofman A, van Bemmel JH, Grobbee DE: QTc Dispersion predicts cardiac mortality in the elderly; The Rotterdam Study: Circulation 1998; 97:467-472.

26. Schouten VJA, Vliegen HW, van der Laarse A, Huysmans HA. Altered calcium handling at normal contractility in hypertrophied rat heart. J Mol Cell Cardiol 1990; 22(9):987-988.

27. Fu GS, Meissner A, Simon R. Repolarization dispersion and sudden cardiac death in patients with impaired left ventricular function. Eur Heart J 1997; 18:281-289. 